\title{
Characterisation of corona-generated ions used in a Neutral cluster and Air Ion Spectrometer (NAIS)
}

\author{
H. E. Manninen ${ }^{1}$, A. Franchin ${ }^{1}$, S. Schobesberger ${ }^{1}$, A. Hirsikko ${ }^{1}$, J. Hakala ${ }^{1}$, A. Skromulis ${ }^{2}$, J. Kangasluoma $^{1}$, \\ M. Ehn ${ }^{1}$, H. Junninen ${ }^{1}$, A. Mirme ${ }^{3}$, S. Mirme ${ }^{3}$, M. Sipilä ${ }^{1}$, T. Petäjä ${ }^{1}$, D. R. Worsnop ${ }^{1,4,5}$, and M. Kulmala ${ }^{1}$ \\ ${ }^{1}$ Department of Physics, P.O. Box 64, 00014 University of Helsinki, Finland \\ ${ }^{2}$ Natural Sciences and Engineering Department, Rezekne Higher Education Institution, Atbrivosanas aleja 90, \\ Rezekne, LV 4601, Latvia \\ ${ }^{3}$ Institute of Physics, University of Tartu, Ülikooli 18, 50090 Tartu, Estonia \\ ${ }^{4}$ Finnish Meteorological Institute, Research and Development, P.O. Box 503, 00101 Helsinki, Finland \\ ${ }^{5}$ Aerodyne Research Inc, Billerica, MA 01821, USA
}

Received: 10 January 2011 - Published in Atmos. Meas. Tech. Discuss.: 6 April 2011

Revised: 8 November 2011 - Accepted: 24 November 2011 - Published: 16 December 2011

\begin{abstract}
We characterized size and chemical composition of ions generated by a corona-needle charger of a Neutral cluster and Air Ion Spectrometer (NAIS) by using a high resolution differential mobility analyzer and a time-of-flight mass spectrometer. Our study is crucial to verify the role of corona-generated ions in the particle size spectra measured with the NAIS, in which a corona charger is used to charge aerosol particles down to the size range overlapping with the size of generated ions. The size and concentration of ions produced by the corona discharging process depend both on corona voltage and on properties and composition of carrier gas. Negative ions were $<1.6 \mathrm{~nm}\left(0.8 \mathrm{~cm}^{2} \mathrm{~V}^{-1} \mathrm{~s}^{-1}\right.$ in mobility) in all tested gas mixtures (nitrogen, air with variable mixing ratios of water vapour), whereas positive ions were $<1.7 \mathrm{~nm}\left(0.7 \mathrm{~cm}^{2} \mathrm{~V}^{-1} \mathrm{~s}^{-1}\right)$. Electrical filtering of the corona generated ions and not removing all charged particles plays an important role in determining the lowest detection limit. Based on our experiments, the lowest detection limit for the NAIS in the particle mode is between 2 and $3 \mathrm{~nm}$.
\end{abstract}

\section{Introduction}

In aerosol size measurements of sub-5 $\mathrm{nm}$ particles based on electrical mobility analysis, the most crucial step is the particle charging process. Electrostatic charging by corona dischargers is commonly used in electrical mobility classifica-

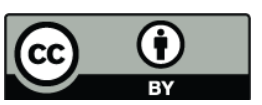

Correspondence to: H. E. Manninen (hanna.manninen@helsinki.fi) tion. Different corona charger designs have been developed and tested in various conditions to optimise particle charging efficiency and to minimise losses of ions and particles inside the chargers (Hernandez-Sierra et al., 2003; Unger et al., 2004; Biskos et al., 2005; Qi et al., 2007; review by Intra and Tippayawong, 2009). The charging efficiency, average charge of particles and their penetration through the charger depend on corona voltage, particle diameter and residence time (e.g. Tamm et al., 1992; Hernandez-Sierra, 2003; Biskos et al., 2005; Intra and Tippayawong, 2009, 2010). The size and number concentration of small ions formed inside the charger have been characterised for some corona chargers (Tamm et al., 1992; Nagato and Owaga, 1998; HernandezSierra et al., 2003; Alonso et al., 2009). The chemical composition of these ions depends on trace gas compounds and residence time (e.g. Skalny et al., 2004; Nagato et al., 2006; Sekimoto and Takayama, 2007). Experiments with corona dischargers have focused on particles in the diameter range from $4 \mathrm{~nm}$ to $\sim 1 \mu \mathrm{m}$ (e.g. Pui et al., 1988; Unger et al. 2004; Tan and Wexler, 2007).

Our focus is to study particle charging down to nanometer sizes with a Neutral cluster and Air Ion Spectrometer (NAIS, Airel Ltd, Kulmala et al., 2007). Controlled charging of the aerosol sample with a corona-needle charger, together with electrical filtering of the corona-generated ions, enables the detection of both neutral and charged aerosol particles. Although the NAIS is a recently developed instrument, it has been already widely used in field studies of atmospheric particle formation (Manninen et al., 2010; Hirsikko et al., 2011 and reference therein). The NAIS has been calibrated and found to be in good agreement with reference instruments

Published by Copernicus Publications on behalf of the European Geosciences Union. 
(Asmi et al., 2009). It was concluded that NAIS can be reliably used as the first instrument to measure ions and particles near sizes $(\sim 1.5-2 \mathrm{~nm})$ where atmospheric particle formation takes place (e.g. Kulmala et al., 2007). The NAIS measures the distribution of both charged and neutral particles in the mobility range $3.16-0.0013 \mathrm{~cm}^{2} \mathrm{~V}^{-1} \mathrm{~s}^{-1}$, which corresponds to a mobility diameter range of $0.8-42 \mathrm{~nm}$. All diameters are reported as Millikan-Fuchs equivalent mobility diameters (Mäkelä et al., 1996; Ku and de la Mora, 2009; Ehn et al., 2011). However, according to Asmi et al. (2009) the ions produced by corona discharge have a mobility range of $1.3-1.6 \mathrm{~cm}^{2} \mathrm{~V}^{-1} \mathrm{~s}^{-1}$, which results in a lower detection limit of approximately $2 \mathrm{~nm}$ for the NAIS when neutral particles are charged for electrical mobility classification. Particles below mobility diameter $\sim 2 \mathrm{~nm}$ cannot be reliably distinguished from corona-generated ions.

This paper presents a verification of the performance of the corona-needle charger used in the NAIS. Efficient filtering of corona-generated ions but not the charged particles at different operating conditions is essential for electrical detection of charged particles down to as small sizes as possible. The lower detection limit of the NAIS is determined by the charging probability, particle concentration and ion mobilities. To estimate how much the corona-generated ions hinder the NAIS particle measurements at the size range overlapping with these ions, we experimentally characterized (1) corona-generated ion number size distribution for different carrier gas mixtures (e.g. filtered compressed air, nitrogen, humidified air, and air mixed with test particles), (2) chemical composition of the ions, and (3) charging of sub- $4 \mathrm{~nm}$ neutral particles while post-filtering the ions away electrically.

\section{Methods and instrumentation}

The following paragraphs give an overview of the experimental set-up and instruments used to characterize the performance of the unipolar corona charger used in the NAIS.

\subsection{Diffusion corona-needle charger of NAIS}

Although the ion spectrometers, such as an Air Ion Spectrometer (AIS, Mirme et al., 2007), detect freshly formed charged particles in the size range well below $1.5-2 \mathrm{~nm}$, the majority of these freshly formed particles are uncharged (Kulmala et al., 2007; Manninen et al., 2010; Lehtipalo et al., 2010). Therefore, measurements of neutral particles below $3 \mathrm{~nm}$ are necessary. The NAIS is a modified version of the AIS instrument and includes several improvements: controlled charging of the aerosol sample and the filtering of the corona-generated ions. The NAIS consists of two independent spectrometer columns, one of each polarity, where the ions are classified by a cylindrical Differential Mobility

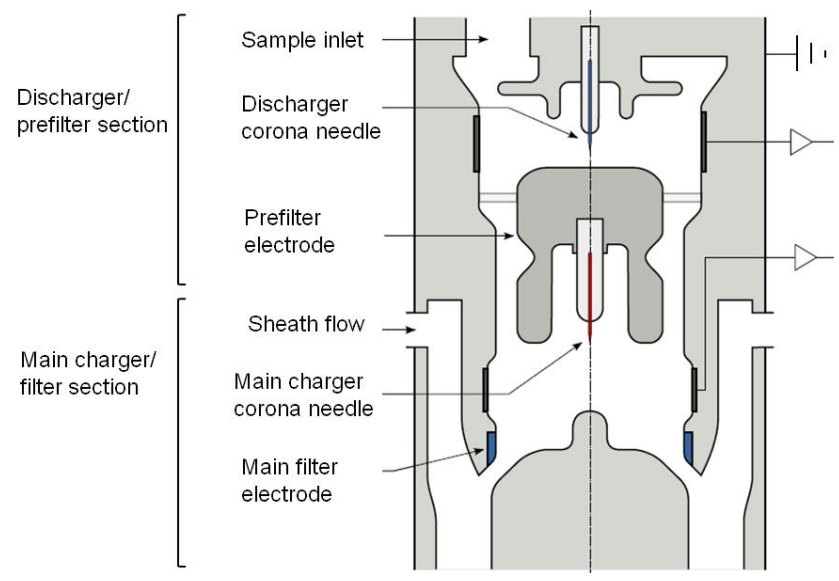

Fig. 1. A schematic cross section diagram of the NAIS aerosol processing unit including two pairs of corona-needle charger and electrical filter sections.

Analyzer (DMA). The NAIS may be divided into two units: aerosol processing and aerosol detection unit.

The processing unit consists of two corona charger and electrostatic filter sections, where the aerosol sample is treated according to the operation mode prior to the mobility analyzers. The aerosol processing unit includes two sections: (1) the discharger + pre-filter, and (2) the main charger + filter section (Fig 1). The NAIS aerosol processing unit has three operation modes: (1) an offset (zero) mode, when only the discharger is used to charge the aerosol sample in the opposite polarity of the analyzer and the pre-filter is used to remove all the charged particles, (2) a particle mode, when only the main charger is used to charge the aerosol sample to the analyzer polarity and the main filter is used to remove ions generated by the charger, and (3) an ion mode, when both sections are switched off.

In the detection unit the charged sample is classified and collected in the 21 electrometer rings in the outer cylinder according to their electrical mobility, and the ion currents are measured with the electrometers. The channels up to 12 are located quite densely on the mobility scale to provide higher mobility resolution at the cluster ion range (negative cluster ions $>1.7 \mathrm{~cm}^{2} \mathrm{~V}^{-1} \mathrm{~s}^{-1}$, positive $>1.3 \mathrm{~cm}^{2} \mathrm{~V}^{-1} \mathrm{~s}^{-1}$ ). The sample and sheath flows of the analyzers are 30 and $601 \mathrm{~min}^{-1}$, respectively. A detailed operation principle and a schematic diagram of the NAIS are presented in Manninen et al., 2009.

The main body of the corona chargers in the NAIS is made of conducting aluminum and Teflon insulator parts. A platinum needle with $0.08 \mathrm{~mm}$ diameter and $4 \mathrm{~mm}$ length maintained at positive/negative high-voltage is used to produce a positive/negative corona discharge in the carrier gas. The discharge is produced in an electrostatic field established in an air stream between the concentric needle and a grounded cylinder (Fig. 1). The corona discharge causes a very rapid 
increase in the number of free electrons and ions in the immediate vicinity of the needle. Due to collisions with the free electrons, molecule bound electrons receive sufficient energy to escape from the molecules. The electrons and positive ions move in opposite directions in the electric field, colliding with other molecules and subsequently producing more ions in the corona discharge area. The corona-generated ions and aerosol particles of nanometer sizes collide due to thermal motion and the particles can become charged. This process is called diffusion charging. By monitoring and controlling the ion current arriving at the walls of the cylinder, the ion production can be determined and maintained at a constant level.

\subsection{High resolution DMA}

The mobility distribution of ions produced in the NAIS corona charger was measured with a high resolution Herrmann Differential Mobility Analyzer (HDMA, Eichler, 1997; de Juan and Fernández de la Mora, 1998; Herrmann et al., 2000). In the HDMA the aerosol flow rate was approximately $151 \mathrm{~min}^{-1}$, with a sheath flow of approximately $20001 \mathrm{~min}^{-1}$. For these operating conditions, the HDMA has an improved mobility resolution with a full width at half maximum (FWHM) of its transfer function of $2 \%$ at $1.5 \mathrm{~nm}$ (Asmi et al., 2009). The mobility range of the HDMA is $7.5-0.1 \mathrm{~cm}^{2} \mathrm{~V}^{-1} \mathrm{~s}^{-1}$, which corresponds to a mobility diameter range of $0.5-4.5 \mathrm{~nm}$. The HDMA was calibrated every day before starting the measurements, for establishing an accurate voltage to mobility conversion using mobility standards (Ude and Fernández de la Mora, 2005). Coronagenerated ions and charged test particles were classified with the HDMA and detected with an aerosol electrometer (TSI 3068B).

\subsection{APi-TOF mass spectrometer}

An Atmospheric Pressure Interface Time-Of-Flight mass spectrometer (APi-TOF, Tofwerk AG, Ehn et al., 2010; Junninen et al., 2010) was used to measure the mass/charge ratios of corona-generated ions, from which we can find quite accurately $(<20 \mathrm{ppm})$ their exact masses which correspond to certain elemental compositions. Comparing the isotopic patterns of those elemental compositions with the patterns observed, further aid us in determining the actual chemical composition of the ions. The APi-TOF measures mass spectra of small ions below a few nanometers with minimal perturbation of the sample. The operating mass range of the instrument was roughly $8-2500 \mathrm{Th}$ (corresponding to $0.2-$ $2.25 \mathrm{~nm}$, Ehn et al., 2011). The TOF is the same as used in the Aerodyne high-resolution aerosol mass spectrometer (DeCarlo et al., 2006) and Ionicon PTR-TOF (Jordan et al., 2009). The APi-TOF was connected in parallel with the electrometer, both sampling from the HDMA outflow (Fig. 2).

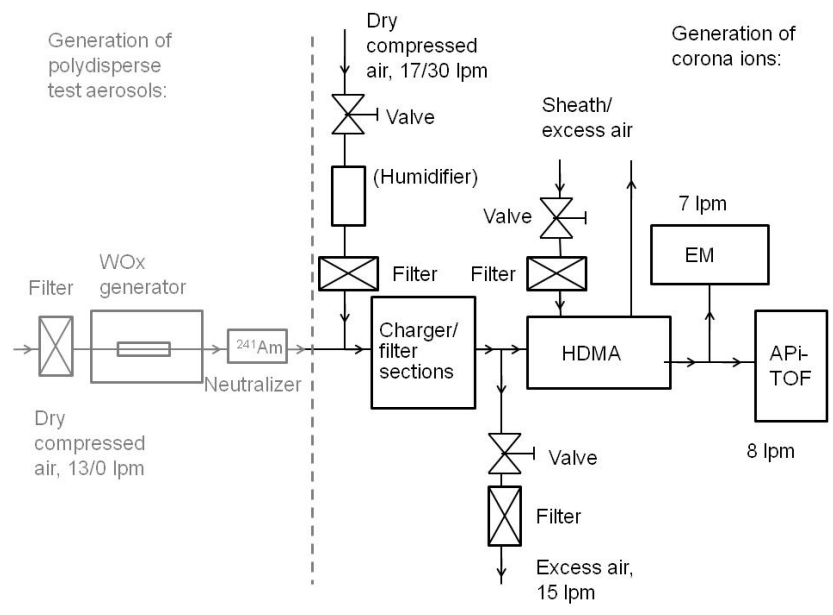

Fig. 2. A schematic layout of the experimental set-up. The layout printed in black was used to investigate the corona-generated ions and the part printed in gray was used when the WOx particles were introduced to the system to be charged by the corona ions.

\subsection{Experimental set-up}

To examine the performance of the NAIS main charger, we measured simultaneously the size distribution and composition of the ions produced by corona discharge. Figure 2 shows a schematic diagram of the experimental set-up for characterizing the ions. The aerosol processing unit (Fig. 1) was disconnected from the NAIS and moved to the experimental set-up. The flow rate through the processing unit was $301 \mathrm{~min}^{-1}$, corresponding to the sample flow rate of the NAIS. For the sample air mixture we used (1) filtered compressed air, (2) humidified filtered compressed air, and (3) instrument grade (5.0) nitrogen. For preliminary characterisation of ions (results presented in chapters 3.1-3.3), we used the set-up illustrated on the right side of the dashed line in Fig. 2. To test the generation of positive and negative ions in the main charging unit, DC voltage (corona voltage) was applied to the corona-needle in the range from -5 to $+5 \mathrm{kV}$. The efficiency of the electrical filters was tested by varying the voltage applied to the filter electrode (filter voltage) in the range of $0-150 \mathrm{~V}$.

The humidifier, which was used especially in the experiments shown in chapter 3.2 (Fig. 5), consists of a $6 \mathrm{~mm}$ Gore-Tex tube inside a bigger steel tube with a layer of water between the tubes. A heating cable is wrapped around the outer steel tube. By heating the water between the tubes, more water vapor diffuses to the sample flow inside the GoreTex tubing, thus increasing the relative humidity (RH) of the aerosol sample. The RH of the sample flow is measured after the humidifier with an integrated humidity and temperature transmitter (Vaisala Humitter 50U, $\pm 5 \% \mathrm{RH}$ ). A PID controller was used for an active feedback to adjust the heating cable current to set and keep the desired RH. 


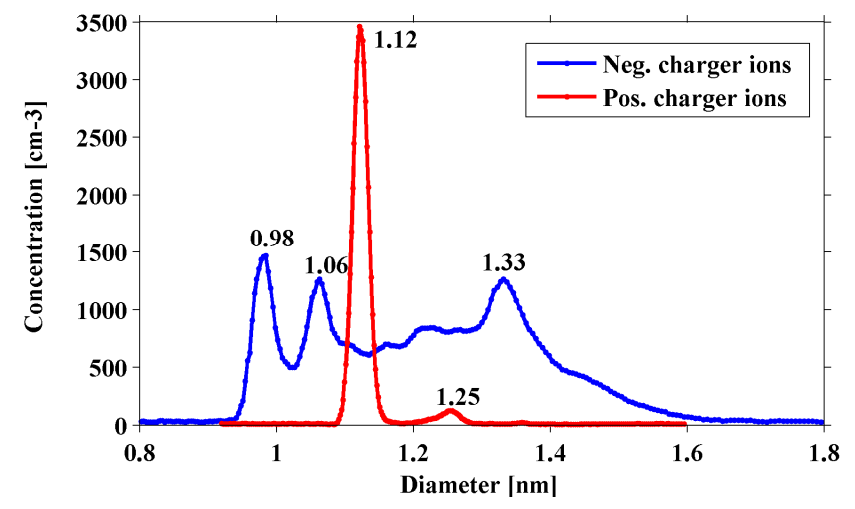

Fig. 3. The median mobility diameter distribution of negative and positive ions produced by corona discharge when $\pm 3 \mathrm{kV}$ was applied to the corona-needle and the carrier gas was filtered compressed air.

For evaluation of the corona charger with test particles (results presented in chapter 3.4), particles in the size range of $1.5-5 \mathrm{~nm}$ were generated with a WOx generator (Tungsten Particle Generator, GRIMM 7.860), shown on the left side of the dash-line in Fig. 2. Since the particles exiting the generator are electrically charged, an ${ }^{241} \mathrm{Am}(360 \mathrm{MBq})$ neutralizer together with the electrical pre-filter of the aerosol processing unit were used to obtain neutral test particles. The test aerosols were diluted with filtered makeup air to provide $301 \mathrm{~min}^{-1}$ flow through the aerosol processing unit. We investigated charging of particles in the main corona charger and the filtering efficiency of the ions generated in the corona charger. In the particle measurements with the NAIS, the main filter section removes corona-generated ions which overlap with nanometer sized particles. In other words, the aim is to remove generated ions but not charged particles. However, the filter removes all charged particles smaller than a certain size (i.e. charged particles with large enough mobility) from the sample air. Therefore, correct adjustment of the main filter is essential for particle detection in the mobility analyzer following the aerosol processing unit.

\section{Results and discussion}

\subsection{Size distribution of corona-generated ions}

The size distribution of negative corona-generated ions (Fig. 3) spreads out over a large diameter range having 5 maxima between mobility diameters of $0.98 \mathrm{~nm}$ and $1.3 \mathrm{~nm}$ $\left(2.3 \mathrm{~cm}^{2} \mathrm{~V}^{-1} \mathrm{~s}^{-1}\right.$ and $\left.1.2 \mathrm{~cm}^{2} \mathrm{~V}^{-1} \mathrm{~s}^{-1}\right)$, whereas the distribution of positive ions had two maxima at $1.1 \mathrm{~nm}$ and $1.2 \mathrm{~nm}$ $\left(1.7 \mathrm{~cm}^{2} \mathrm{~V}^{-1} \mathrm{~s}^{-1}\right.$ and $\left.1.4 \mathrm{~cm}^{2} \mathrm{~V}^{-1} \mathrm{~s}^{-1}\right)$. The mean mobility diameter was $1.1 \mathrm{~nm}\left(1.6 \mathrm{~cm}^{2} \mathrm{~V}^{-1} \mathrm{~s}^{-1}\right)$ for positive ions and $1.0 \mathrm{~nm}\left(1.8 \mathrm{~cm}^{2} \mathrm{~V}^{-1} \mathrm{~s}^{-1}\right)$ for negative ions. The mean residence time of corona-generated ions was approximately $500 \mathrm{~ms}$ between the corona needle tip and the inlet of the
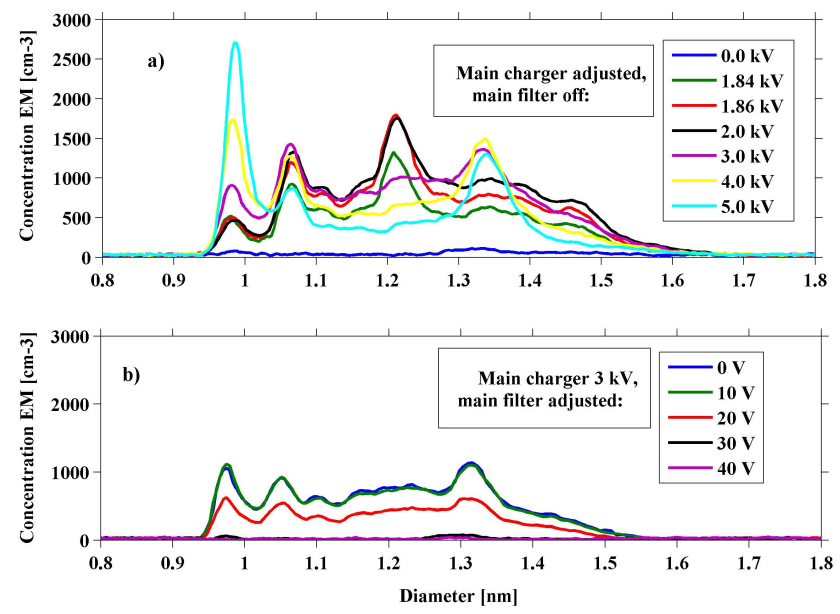

Fig. 4. Median size distribution of negative corona-generated ions as a function of (a) negative corona voltage applied to the needle and (b) negative voltage applied to the main filter when corona voltage was kept constant at $-3 \mathrm{kV}$.

DMA (Fig. 2). It should be noted that ion distributions change rapidly on a $\mu$ s time scale after being produced, and it is difficult to duplicate exact instrument times in the experimental set-up. However, we believe that residence times here are long enough that changes are no longer rapid; thus, our results are applicable to the system we are attempting to characterize. The relatively small ion concentrations measured with our set-up reflect the high flow rate of the aerosol, electrostatic losses in the charging region, diffusion losses in the sample lines, short life time of the ions and the HDMA transmission efficiency. The difference in concentration between polarities is due to higher loss rate of more mobile negative ions. Typically, the number concentration of charger ions varies from $10^{4}$ to $10^{7}$ ions $\mathrm{cm}^{-3}$ depending on the applied conditions in each particular case (Hernandez-Sierra, 2003; Intra and Tippayawong, 2010).

We studied the size spectra of ions generated by the corona discharge as a function of applied voltage and polarity. The mobility diameter distributions of negative ions are shown in Fig. 4a as a function of corona voltage. All spectra were measured with a fixed flow rate of filtered compressed air (with RH close to zero) through the charger. The negative mobility diameter spectra seem to change significantly with the corona voltage: the peak diameter value shifted from 1.2 to approximately $1.0 \mathrm{~nm}\left(1.4\right.$ and $2.1 \mathrm{~cm}^{2} \mathrm{~V}^{-1} \mathrm{~s}^{-1}$, respectively). Four peaks in the negative ion distribution were usually distinguished between 1.0 and $1.3 \mathrm{~nm}$ (2.1 and $1.2 \mathrm{~cm}^{2} \mathrm{~V}^{-1} \mathrm{~s}^{-1}$ ). With low corona voltage the peak diameter is in the middle of this range, and increasing the voltage reveals a tendency of the negative ions to evolve and have only two peaks: at $1.0 \mathrm{~nm}$ and $1.3 \mathrm{~nm}$. The positive ion size spectra had three peaks at $1.1,1.2$ and $1.4 \mathrm{~nm}$ (1.6, 1.3 and $\left.1.1 \mathrm{~cm}^{2} \mathrm{~V}^{-1} \mathrm{~s}^{-1}\right)$, and increasing the corona voltage elevated the total ion concentration but the peak sizes 
did not change. In general, the negative ions were smaller than $1.6 \mathrm{~nm}\left(0.8 \mathrm{~cm}^{2} \mathrm{~V}^{-1} \mathrm{~s}^{-1}\right)$ in all conditions when measured with the HDMA, whereas the positive ions were below $1.7 \mathrm{~nm}\left(0.7 \mathrm{~cm}^{2} \mathrm{~V}^{-1} \mathrm{~s}^{-1}\right)$. These results are in good agreement with the NAIS corona charger experiments by Asmi et al. (2009), and other corona charger experiments (Nagato and Owaga, 1998; Hernandez-Sierra et al., 2003; Alonso et al., 2009).

The efficiency of the electrical main filter as a function of voltage applied to the filter electrode is illustrated in Fig. 4b. The figure suggests that the main filter is able to remove all the small corona-generated ions from the spectra already with a relatively low voltage $( \pm 30-40 \mathrm{~V})$. Increasing the filter voltage from $10 \mathrm{~V}$ to $20 \mathrm{~V}$ decreased the concentration of the ions equally for all the sizes. In normal operating conditions of the NAIS the corona-needle voltage is in the range of $2-3 \mathrm{kV}$ and the filter operates with a voltage of $70-100 \mathrm{~V}$, therefore the ions are removed more efficiently. In all experiments presented in chapters 3.1-3.3, the pre-filter, which is normally operated during offset measurements, was used to remove all sub- $4 \mathrm{~nm}$ charged particles with a filter voltage $\pm 50 \mathrm{~V}$ before they reach the main charger region. As the carrier gas was already filtered, particle-free air, the pre-filtering was only a precaution.

\subsection{Effect of carrier gas}

The presence of water vapour strongly modifies the chemical composition of ions produced by corona discharge (Skalny et al., 2004; Nagato et al., 2006). Therefore, we investigated the effect of carrier gas mixture and in particularly the role of RH to mobility spectra. Also our results indicate that the corona charger ion production rate and the size distribution depend strongly on the particle/gas mixture and on relative humidity (Fig. 5). The peak of the negative ion size distrubution, upper panel in Fig. 5, shifted towards larger sizes as the RH increased indicating an accumulation of water molecules on the clusters. The positive charger ions, lower panel in Fig. 5, had a similar behaviour. The positive charger ion size distribution had a peak at $1.1 \mathrm{~nm}$, and as the RH increased, the maximum shifted to $1.25 \mathrm{~nm}$. In addition, the number of peaks both in the positive and negative ions size distribution changes as a function of RH.

The size distributions of positive and negative ions measured in humidified carrier gas (Fig. 5) agree well with the corona-generated ion size distributions observed by e.g. Nagato and Owaga, 1998; Alonso et al. 2009; Asmi et al., 2009; and Junninen et al., 2009. Based on their data, positive and negative ions had approximately five and two peaks in the mobility spectra, respectively, when filtered (also dried with silica gel in Alonso et al. 2009) room air was used as the carrier gas. On the contrary, we detected size distributions with two peaks for positive ions and approximately five peaks for negative ions (Fig. 3) when we used dried, filtered compressed (room) air, which had an RH close to zero. However,

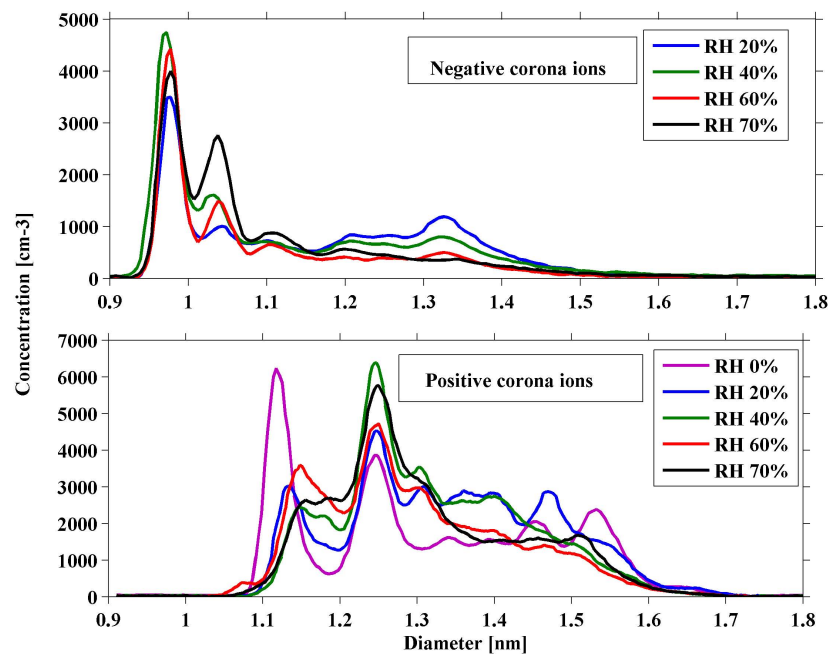

Fig. 5. Median size distributions of negative and positive ions generated by the corona discharge as a function of relative humidity $(\mathrm{RH})$. The corona voltage was $\pm 3 \mathrm{kV}$.

the location of the peaks seemed to be more or less the same in all studies.

Figures 5 and 6 illustrate clearly how the ion production rate, and thus the size distribution, depends on the carrier gas mixture. The blue solid line in Fig. 6 represents the ion size spectra at low relative humidity, whereas the red solid line represents the humidified size spectra. In these two cases the measured size distributions differ significantly. It should be noted that the data points represented by red line was measured when carrier gas was additionally "dried" with a silica gel. The compressed air used in this study has a dew point of $-36^{\circ} \mathrm{C}$, which in room temperature $\left(25^{\circ} \mathrm{C}\right)$ correspond to very low RH of $\sim 0.6 \%$. When the silica gel was added to the set-up, it actually increased the RH as the extremely dry compressed air was "drying" the silica gel - not the other way round.

In our experiments, the residence time of the coronagenerated ions in the sample flow (between the tip of the corona needle and the inlet of the DMA) was longer than the time the ions drift inside the NAIS. The ions moved in approximately $50-90 \mathrm{~ms}$ assuming a plug flow from the main corona charger to the top of the analyzer where the ion concentration is measured. As mentioned, ion composition changes with time (e.g. Nagato et al., 2006), and thus we studied the changes in generated ion size distributions using flow rates ranging from 28 to $311 \mathrm{~min}^{-1}$ through the charger. This $10 \%$ variation of the flow rate did not significantly change the size distribution, indicating that no rapid changes occurred on these time scales. A shift to larger sizes with decreasing flow was not observed, which also supports the idea presented by Alonso et al. (2009), suggesting that varying the flow rate of air through the charger is not a proper approach to study the effect of ion aging alone. 
Table 1. Listing of some major negative and positive compounds in the ion spectra recorded using the APi-TOF. Names are given for the corresponding not deprotonated (negative ions) or protonated (positive ions) compounds. Molecular formulas in italics are not unambiguously identified.

\begin{tabular}{|c|c|c|c|}
\hline \multicolumn{2}{|c|}{ Identified negative ions } & \multicolumn{2}{|c|}{ Identified positive ions } \\
\hline integer m/Q (Th) & Molecular formula & Integer $\mathrm{m} / \mathrm{Q}(\mathrm{Th})$ & Molecular formula \\
\hline 62 & $\mathrm{NO}_{3}^{-}$(nitric acid) & 19 & $\mathrm{H}_{3} \mathrm{O}^{+}$(water) \\
\hline 87 & $\mathrm{C}_{3} \mathrm{H}_{3} \mathrm{O}_{3}^{-}$ & 37 & $\mathrm{H}_{2} \mathrm{O} \cdot \mathrm{H}_{3} \mathrm{O}^{+}$ \\
\hline 89 & $\mathrm{C}_{3} \mathrm{H}_{5} \mathrm{O}_{3}^{-}$(lactic acid) & 55 & $\left(\mathrm{H}_{2} \mathrm{O}\right) \cdot \mathrm{H}_{3} \mathrm{O}^{+}$ \\
\hline 97 & $\mathrm{HSO}_{4}^{-}$(sulphuric acid) & 100 & $\mathrm{C}_{5} \mathrm{H}_{10} \mathrm{NO}^{+}$ \\
\hline 101 & $\mathrm{C}_{4} \mathrm{H}_{5} \mathrm{O}_{3}^{-}$ & 114 & $\mathrm{C}_{6} \mathrm{H}_{12} \mathrm{NO}^{+}$ \\
\hline 112 & $\mathrm{SO}_{5}^{-}$ & 130 & $\mathrm{C}_{8} \mathrm{H}_{20} \mathrm{~N}^{+}$ \\
\hline 115 & $\mathrm{C}_{5} \mathrm{H}_{7} \mathrm{O}_{3}^{-}$ & 171 & $\mathrm{C}_{9} \mathrm{H}_{19} \mathrm{~N}_{2} \mathrm{O}^{+}$ \\
\hline 121 & $\mathrm{C}_{7} \mathrm{H}_{5} \mathrm{O}_{2}^{-}$ & 199 & $\mathrm{C}_{5} \mathrm{H}_{9} \mathrm{NO} \cdot \mathrm{C}_{5} \mathrm{H}_{10} \mathrm{NO}^{+}$ \\
\hline 124 & $\mathrm{H}_{2} \mathrm{CO}_{3} \cdot \mathrm{NO}_{3}^{-}$ & 213 & $\mathrm{C}_{6} \mathrm{H}_{11} \mathrm{NO} \cdot \mathrm{C}_{5} \mathrm{H}_{10} \mathrm{NO} \mathrm{O}^{+}$ \\
\hline 125 & $\mathrm{HNO}_{3} \cdot \mathrm{NO}_{3}^{-}$ & 610 & $\left(\mathrm{SiOC}_{2} \mathrm{H}_{6}\right)_{8} \mathrm{OH}_{2}^{+}$ \\
\hline 127 & $\mathrm{I}^{-}$ & 684 & $\left(\mathrm{SiOC}_{2} \mathrm{H}_{6}\right)_{9} \mathrm{OH}_{2}^{+}$ \\
\hline 129 & $\mathrm{C}_{6} \mathrm{H}_{9} \mathrm{O}_{3} \& \mathrm{C}_{5} \mathrm{H}_{5} \mathrm{O}_{4}^{-}$ & 758 & $\left(\mathrm{SiOC}_{2} \mathrm{H}_{6}\right)_{10} \mathrm{OH}_{2}^{+}$ \\
\hline 133 & $\mathrm{C}_{4} \mathrm{H}_{5} \mathrm{O}_{5}^{-}$ & 832 & $\left(\mathrm{SiOC}_{2} \mathrm{H}_{6}\right)_{11} \mathrm{OH}_{2}^{+}$ \\
\hline 135 & $\mathrm{C}_{4} \mathrm{H}_{7} \mathrm{O}_{5}^{-}$ & 906 & $\left(\mathrm{SiOC}_{2} \mathrm{H}_{6}\right)_{12} \mathrm{OH}_{2}^{+}$ \\
\hline 149 & $\mathrm{C}_{4} \mathrm{H}_{5} \mathrm{O}_{6}^{-}$ & 980 & $\left(\mathrm{SiOC}_{2} \mathrm{H}_{6}\right)_{13} \mathrm{OH}_{2}^{+}$ \\
\hline
\end{tabular}

\subsection{Chemical composition of corona-generated ions}

We also characterized the chemical composition of the ions generated in the corona discharger. In these experiments the mobility of the corona-generated ions was preselected using the HDMA, and the ions were subsequently directed to an APi-TOF for mass spectral analysis. It should be noted that the APi-TOF has a mass/charge $(\mathrm{m} / \mathrm{Q})$ dependent transmission which may slightly distort the distributions, and additionally some fragmentation may occur inside the instrument (Junninen et al., 2010; Ehn et al., 2011). For this application, some evaporation, especially of water, occours and fragmentation is a minor issue for this.

Figure 7 shows two typical ion spectra recorded by the APi-TOF: each for positive and negative corona-generated ions. They were sampled in the experiments using filtered compressed air and standard corona charger voltage $( \pm 3 \mathrm{kV})$. The corresponding ion size distributions are depicted in Fig. 3. The ion spectra presented in Fig. 7 are time averages over several tens of minutes, taken with the HDMA set to a single voltage. For recording the positive ion mass spectrum (top panel), one HDMA voltage was chosen, corresponding to the single large peak found in the size spectrum at $1.1 \mathrm{~nm}$ (Fig. 3). The negative ion mass spectrum (bottom panel) is a composite of three single measurements using the HDMA voltages corresponding to the three main peaks of the corresponding size spectrum at $0.98,1.06$ and $1.33 \mathrm{~nm}$ (Fig. 3).

The results show that the positive ion spectrum was dominated by peaks at 100 and $199 \mathrm{Th}$, which are believed to

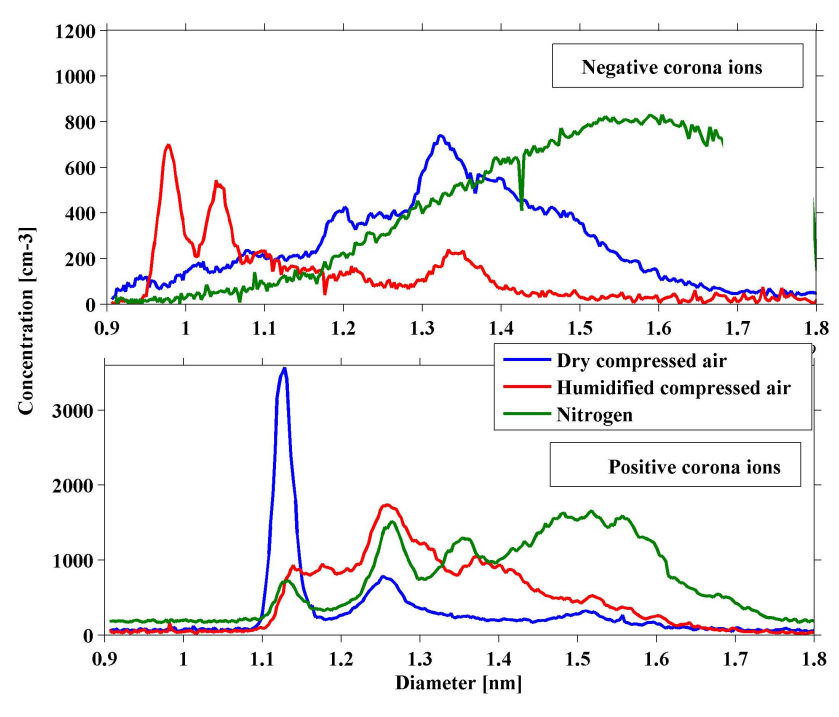

Fig. 6. Size distribution of negative and positive ions generated by the corona discharge with different sample (carrier) gas mixture. The corona voltage was $\pm 3 \mathrm{kV}$.

have the elemental formulas $\mathrm{C}_{5} \mathrm{H}_{10} \mathrm{NO}^{+}$and $\mathrm{C}_{10} \mathrm{H}_{19} \mathrm{~N}_{2} \mathrm{O}_{2}^{+}$, respectively, with the $199 \mathrm{Th}$ peak being the dimer (i.e. $\mathrm{C}_{5} \mathrm{H}_{9} \mathrm{NO} \mathrm{C}_{5} \mathrm{H}_{10} \mathrm{NO}^{+}$) of the $100 \mathrm{Th}$ peak. The molecular composition of $\mathrm{C}_{5} \mathrm{H}_{10} \mathrm{NO}^{+}$is not known, but could be either protonated piperidone or protonated methyl-pyrrolidone. Ehn et al. (2010) reported that the positive ion spectra in the ambient air samples were dominated by compounds with structures similar to these, e.g. pyridines and quinolines 


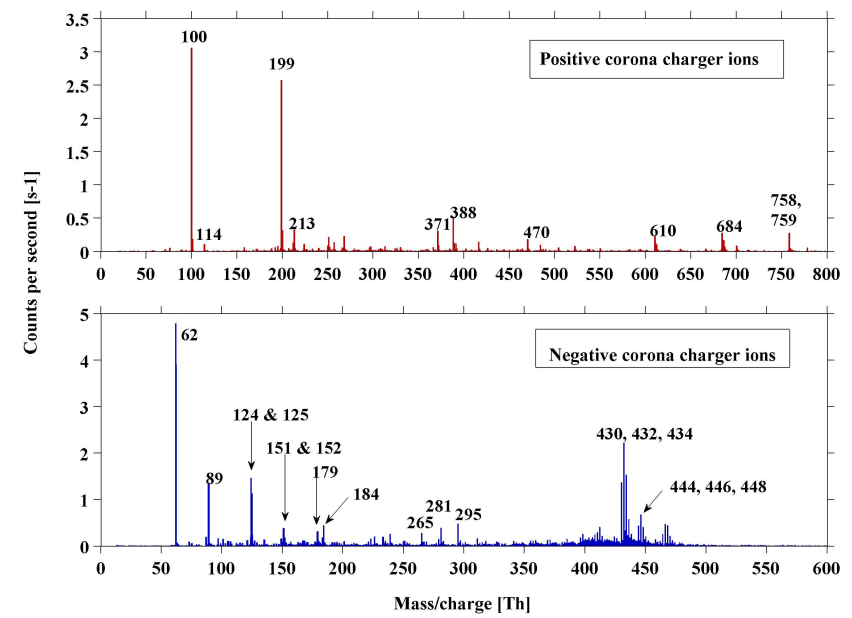

Fig. 7. The mass spectra of negative and positive ions generated by the corona discharge. The corona voltage was $\pm 3 \mathrm{kV}$.

containing a ring of carbon atoms with one carbon atom substituted by a nitrogen atom causing a very high proton affinity. Some identified compounds in laboratory experiments in this study are listed in Table 1. Note the peaks at high $\mathrm{m} / \mathrm{Q}$ have a spacing of $74 \mathrm{Th}$, i.e. 610,684 , and $758 \mathrm{Th}$. These compounds arise from silicone polymers, most likely originating from conductive silicone tubing, a common contaminant in these types of measurements.

The negative ion spectrum was dominated by different acids, ionized by donating a proton. The largest contribution is by the nitrate ion $\mathrm{NO}_{3}^{-}$at $62 \mathrm{Th}$ and dimers thereof at $125 \mathrm{Th}\left(\mathrm{HNO}_{3} \mathrm{NO}_{3}^{-}\right) . \mathrm{NO}_{3}^{-}$is a usual terminal ion, also in ambient air, due to its low proton affinity. It clusters also with carbonic acid $\left(\mathrm{H}_{2} \mathrm{CO}_{3} \mathrm{NO}_{3}^{-}, 124 \mathrm{Th}\right)$, and probably other, heavier acids as well. Other acids identified in the negative ion spectra were e.g. pyruvic acid, lactic acid and benzoic acid. A more detailed list is found in Table 1 . Compounds with peaks at $m / Q$ larger than $\sim 200 \mathrm{Th}$, remain largely unidentified.

The chemical composition of corona-generated ions have been observed to depend on the trace gas composition and time for reactions, as one could expect (e.g. Skalny et al., 2004; Nagato et al., 2006). However, Sekimoto and Takayama (2007) showed that the chemical composition of the ions formed in a corona discharger depends also on the applied voltage.

\subsection{Particle charging and filtering of the corona-generated ions}

As the ions produced by the corona discharge set the lower detection limit of the NAIS, we investigated filtering efficiency of the ions. First, we generated a polydisperse particle population using a tungsten particle generator, and then the particles were charged in the ${ }^{241} \mathrm{Am}$ neutralizer. Sec-

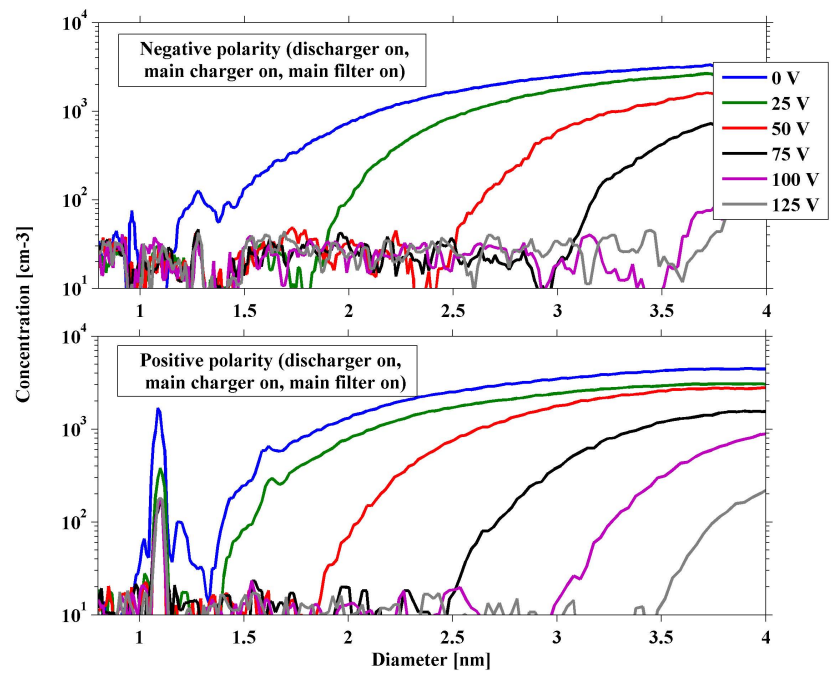

Fig. 8. Filtering of the charged particles with the electrical filter. The panels show the concentration of negative (top) and positive (bottom) corona ions and sample particles as a function of the voltage applied to the main filter electrode.

ond, the electrical pre-filter $( \pm 50 \mathrm{~V})$ removed all charged particles and the main corona section charged the remaining neutral particles. Finally, the main filter of the aerosol processing unit removed small charged particles and the coronagenerated ions. The results indicate that the main corona charger used in the NAIS is able to charge small neutral particles in both polarities equally efficiently for electrical classification (Figs. 8 and 9). Figure 8 shows how the size distribution including corona-generated ions and charged WOx particles shift to larger sizes as the post-filter voltage is increased. Clearly, the figure indicates that the electrical filtering is size dependent as it increases the lowest detection limit of the NAIS with increasing filtering voltage. As shown in Fig. 9, both the ions and the particles charged in the charger were removed by the main filter. The figure shows how positive and negative corona-generated ions of $\sim 1.1$ and $\sim 1.3 \mathrm{~nm}$, respectively, (maximum charger peaks in the size distribution, in Fig. 8) and positively and negatively charged WOx particles of $\sim 3.8$ and $\sim 3.6 \mathrm{~nm}$, respectively, (maximum WOx peaks, in Fig. 8) are removed as a function of voltage applied to the filter electrode. The positive and negative coronagenerated ions were removed (Fig. 9) when the filter voltage was set to approximately $40-50 \mathrm{~V}$. Although the positive ion concentrations were six times higher at the beginning of the experiment, both negative and positive corona-generated ions were filtered at approximately the same filter voltage. With $50 \mathrm{~V}$ only a portion of the WOx particles was removed. According to these two observations, the electrical filtering of the corona-generated ions seemed to be more sensitive to the particle size (mobility) than to the absolute concentration. These results suggest that if we would have generated WOx particles at $2-3 \mathrm{~nm}$ size range the post-filtering with lower 


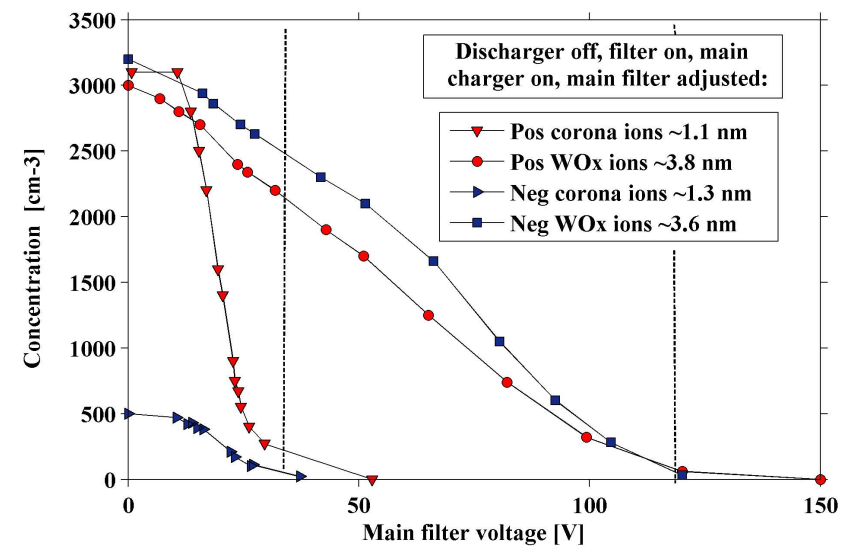

Fig. 9. Filtering of the charged particles with the main electrical filter. The concentration of corona ions and sample particles decreases as a function of the voltage applied to the filter electrode, with most of the charger ions being removed around $30 \mathrm{~V}$. The corona voltage was $\pm 3 \mathrm{kV}$ and pre-filter $\pm 50 \mathrm{~V}$.

voltages would have been more efficient. The dilemma of the post-filter adjusting is how to filter the ions produced by corona discharge without removing the sample particles in the same size range. That voltages used as default values in the NAIS (70-100 V) seem to be adequate in filtering out the corona-generated ions and still leaving some of the initially neutral particles at the $2-3 \mathrm{~nm}$ size to be detected by the electrometers in the instrument.

\section{Conclusions}

We present size distribution measurements of both positive and negative ions produced by corona discharge under different conditions. The chemical composition of the ions was characterized in parallel with the size measurements. The aim was to characterise both the size and chemical composition of the ions generated by a corona-needle charger from the Neutral cluster and Air Ion Spectrometer (NAIS) with the state-of-art instrumentation. Our results indicate that in the corona discharging process the size and the concentration of ions depend both on the corona voltage and on the physical and chemical properties of the carrier gas mixture. The role of the water vapour is pronounced. The results of this study help in understanding the large scattering of ion mobility values given in the earlier publications (Nagato and Ogawa, 1998; Hernandez-Sierra et al., 2003; Alonso et al., 2009; Asmi et al., 2009).

We characterized the corona-generated ions with a high resolution DMA, which has a narrow transfer function (FWHM of $2 \%$ at $1.5 \mathrm{~nm}$ ), whereas the NAIS transfer functions are quite broad due to low resolution. This has to be considered when determining the lowest theoretical particle detection limit of the NAIS. At normal atmospheric pressure the ratio of sample and sheath flows of the NAIS is 1:2, producing wide transfer functions (Knutson and Whitby 1975) and spreading the detection of corona-generated ions to several channels (Asmi et al., 2009). Therefore, part of these ions is detected also at bigger sizes by the NAIS. According to our results negative corona generated ions were $<1.6 \mathrm{~nm}$ and positive ions $<1.7 \mathrm{~nm}$, the lowest detection limit of the NAIS can be set between 2 to $3 \mathrm{~nm}$, being smaller in the negative and larger in the positive polarity. The limit could be further decreased if the measured small particle concentration is high when an even larger fraction of the coronagenerated ions is used to charge the sample particles. In this case we don't need to filter as much to reach as low coronagenerated ion concentrations after the main charger.

Further study of the corona discharger and its effect on the NAIS spectra is necessary. Especially, some guidelines for adjusting the electrical filter to remove the coronagenerated ions should be given. The results presented in this paper can function as preliminary guidelines until more detailed measurements have been conducted. Optimally, the corona-generated ions hindering the measurement signal of the NAIS can be accurately determined and subtracted for any given operation condition.

Acknowledgements. The researchers working at the University of Tartu and Airel Ltd are acknowledged for their help throughout the studies. This work has been supported by European Commission 6th Framework program projects: EUCAARI, contract no 036833-2 (EUCAARI). The financial support by the Academy of Finland Centre of Excellence program (project no. 1118615) is also gratefully acknowledged. A. F. and S. S. acknowledges the support from the European Community under the FP7 Marie Curie Initial Training Network "CLOUD-ITN" (PITN-GA-2008-215072). A. H. acknowledges the support from Maj and Tor Nessling foundation (Grant No. 2007116).

Edited by: H. Schlager

\section{References}

Alonso, M., Santos, J. P., Hontañón, E., and Ramiro, E.: First Differential Mobility Analysis (DMA) Measurements of Air Ions Produced by Radioactive Source and Corona, Aerosol Air Qual. Res., 9, 453-457, 2009.

Asmi, E., Sipilä, M., Manninen, H. E., Vanhanen, J., Lehtipalo, K., Gagné, S., Neitola, K., Mirme, A., Mirme, S., Tamm, E., Uin, J., Komsaare, K., Attoui, M., and Kulmala, M.: Results of the first air ion spectrometer calibration and intercomparison workshop, Atmos. Chem. Phys., 9, 141-154, doi:10.5194/acp-9-141-2009, 2009.

Biskos, G., Reavell, K., and Collings, N.: Unipolar diffusion charging of aerosol particles in the transition regime. J. Aerosol Sci., 36, 247-265, 2005.

De Juan, L. and Fernandez De La Mora, J.: Sizing nanoparticles with a focusing impactor: Effect of the collector size, J. Aerosol Sci., 29, 589-599, 1998. 
DeCarlo, P. F., Kimmel, J. R., Trimborn, A., Northway, M. J., Jayne, J. T., Aiken, A. C., Gonin, M., Fuhrer, K., Horvath, T., Docherty, K., Worsnop, D. R., and Jimenez, J. L.: Field-Deployable, HighResolution, Time-of-Flight Aerosol Mass Spectrometer, Anal. Chem., 78, 8281-8289, 2006.

Ehn, M., Junninen, H., Petäjä, T., Kurtén, T., Kerminen, V.-M., Schobesberger, S., Manninen, H. E., Ortega, I. K., Vehkamäki, H., Kulmala, M., and Worsnop, D. R.: Composition and temporal behavior of ambient ions in the boreal forest, Atmos. Chem. Phys., 10, 8513-8530, doi:10.5194/acp-10-8513-2010, 2010.

Eichler, T.: A Differential Mobility analyzer for ions and nanoparticles: Laminar flow at high Reynolds numbers. Senior Graduation Thesis presented to Fachhochscule Offenburg, Germany, 1997.

Ehn, M., Junninen, H., Schobesberger, S., Manninen, H. E., Franchin, A., Sipilä, M., Petäjä, T., Kerminen, V.-M., Tammet, H., Mirme, A., Mirme, S., Hõrrak, U., Kulmala, M., and Worsnop, D. R.: Comparing mobility and mass measurements of atmospheric small ions, Aerosol Sci. Technol., 45, 522-532, 2011.

Hernandez-Sierra, A., Alguacil, F. J., and Alonso, M.: Unipolar charging of nanometer aerosol particles in a corona ionizer, J. Aerosol Sci., 34, 733-745, 2003.

Herrmann, W., Eichler, T., Bernardo, N., and Fernández de la Mora, J.: Turbulent transition arises at Re 35000 in a short Viennatype DMA with a large laminarizing inlet, Abstract to the annual conference of the AAAR, St. Louis, MO, 6-10 October, 2000.

Hirsikko, A., Nieminen, T., Gagné, S., Lehtipalo, K., Manninen, H. E., Ehn, M., Hõrrak, U., Kerminen, V.-M., Laakso, L., McMurry, P. H., Mirme, A., Mirme, S., Petäjä, T., Tammet, H., Vakkari, V., Vana, M., and Kulmala, M.: Atmospheric ions and nucleation: a review of observations, Atmos. Chem. Phys., 11, 767798, doi:10.5194/acp-11-767-2011, 2011.

Intra, P. and Tippayawong, N.: Progress in unipolar corona discharger designs for airborne particle charging: A literature review, J. Electrostatics, 67, 605-615, 2009.

Intra, P. and Tippayawong, N.: Effect of needle cone angle and air flow rate on electrostatic discharge characteristics of a coronaneedle ionizer, Journal of Electrostatics, 68, 254-260, 2010.

Jordan, A., Haidacher, S., Hanel, G., Hartungen, E., Märk, L., Seehauser, H., Schottkowsky, R., Sulzer, P., and Märk, T. D.: A high resolution and high sensitivity proton-transfer-reaction time-of-flight mass spectrometer (PTR-TOF-MS), Int. J. Mass Spectrom., 286, 122-128, 2009.

Junninen, H., Ehn, M., Lehtipalo, K., Steiner, G., Sipilä, M., Attoui, M., Worsnop, D. R., and Kulmala, M.: Characterization of Charger Ions Using High Resolution DMA and Atmospheric Pressure Interface Time of Flight Mass Spectrometer (API-TOFMS), AAAR 28th Annual Conference Abstracts, 1182, 2009.

Junninen, H., Ehn, M., Petäjä, T., Luosujärvi, L., Kotiaho, T., Kostiainen, R., Rohner, U., Gonin, M., Fuhrer, K., Kulmala, M., and Worsnop, D. R.: A high-resolution mass spectrometer to measure atmospheric ion composition, Atmos. Meas. Tech., 3, 1039 1053, doi:10.5194/amt-3-1039-2010, 2010.

Knutson, E. O. and Whitby, K. T.: Accurate measurement of aerosol electric mobility moments, J. Aerosol Sci., 6, 443-451, 1975.

$\mathrm{Ku}, \mathrm{B}$. K. and de la Mora, J.F.: Relation between Electrical Mobility, Mass, and Size for Nanodrops $1-6.5 \mathrm{~nm}$ in Diameter in Air, Aerosol Sci. Tech., 43, 241-249, 2009.
Kulmala, M., Riipinen, I., Sipilä, M., Manninen, H. E., Petäjä, T., Junninen, H., Dal Maso, M., Mordas, G., Mirme, A., Vana, M., Hirsikko, A., Laakso, L., Harrison, R. M., Hanson, I., Leung, C., Lehtinen, K. E. J., and Kerminen, V.-M.: Towards direct measurements of atmospheric nucleation, Science, 318, 89-92, 2007.

Lehtipalo, K., Kulmala, M., Sipilá, M., Petäjä, T., Vana, M., Ceburnis, D., Dupuy, R., and O'Dowd, C.: Nanoparticles in boreal forest and coastal environment: a comparison of observations and implications of the nucleation mechanism, Atmos. Chem. Phys., 10, 7009-7016, doi:10.5194/acp-10-7009-2010, 2010.

Manninen, H. E., Petäjä, T., Asmi, E., Riipinen, I., Nieminen, T., Mikkilä, J., Hõrrak, U., Mirme, A., Mirme, S., Laakso, L., Kerminen, V.-M., and Kulmala, M.: Long-term field measurements of charged and neutral clusters using Neutral cluster and Air Ion Spectrometer (NAIS), Boreal Environ. Res., 14, 591-605, 2009.

Manninen, H. E., Nieminen, T., Asmi, E., Gagné, S., Häkkinen, S., Lehtipalo, K., Aalto, P., Vana, M., Mirme, A., Mirme, S., Hõrrak, U., Plass-Dülmer, C., Stange, G., Kiss, G., Hoffer, A., Törõ, N., Moerman, M., Henzing, B., de Leeuw, G., Brinkenberg, M., Kouvarakis, G. N., Bougiatioti, A., Mihalopoulos, N., O’Dowd, C., Ceburnis, D., Arneth, A., Svenningsson, B., Swietlicki, E., Tarozzi, L., Decesari, S., Facchini, M. C., Birmili, W., Sonntag, A., Wiedensohler, A., Boulon, J., Sellegri, K., Laj, P., Gysel, M., Bukowiecki, N., Weingartner, E., Wehrle, G., Laaksonen, A., Hamed, A., Joutsensaari, J., Petäjä, T., Kerminen, V.-M., and Kulmala, M.: EUCAARI ion spectrometer measurements at 12 European sites - analysis of new particle formation events, Atmos. Chem. Phys., 10, 7907-7927, doi:10.5194/acp-10-79072010, 2010.

Mirme, A., Tamm, A., Mordas, G., Vana, M., Uin, J., Mirme, S., Bernotas, T., Laakso, L., Hirsikko, A. and Kulmala, M.: A Widerange multi-channel Air Ion Spectrometer, Boreal Environ. Res., 12, 247-264, 2007.

Mäkelä, J. M., Riihelä, M., Ukkonen, A., Jokinen, V., and Keskinen, J.: Comparison of mobility equivalent diameter with KelvinThomson diameter using ion mobility data, J. Chem. Phys., 105, 1562-1571, 1996.

Nagato, K. and Ogawa T.: Evolution of tropospheric ions observed by an ion mobility spectrometer with a drift tube, J. Geophys. Res.-Atmos, 103, 13917-13925, 1998.

Nagato, K., Matsui, Y., Miyata, T., and Yamauchi, T.: An analysis of the evolution of negative ions produced by a corona ionizer in air, Int. J. Mass Spec., 248, 142-147, 2006.

Pui, D. Y. H, Fruin, S., and McMurry, P. H.: Unipolar diffusion charging of ultrafine aerosols, Aerosol Sci. Technol., 8, 173-187, 1988.

Qi, C., Chen, D.-R., and Pui, D. Y. H.: Experimental study of a new corona-based unipolar aerosol charger, J. Aerosol Sci., 38, 775-792, 2007.

Sekimoto, K. and Takayama, M.: Influence of needle voltage on the formation of negative core ions using atmospheric pressure corona discharge in air, Int. J. Mass Spec., 261, 38-44, 2007.

Skalny, J. D., Mikoviny, T., Matejcik, S., and Mason, N. J.: An analysis of mass spectrometric study of negative ions extracted from negative corona discharge in air, Int. J. Mass Spec., 233, 317-324, 2004.

Tamm, E., Mirme, A., and Kikas, Ü.: Corona discharge as a generator of nanometer-range monodisperse aerosol, Acta Commentat Univ. Tartu. (1954-1989), 947, 80-88, 1992. 
Tan, Z. C. and Wexler, A. S: Fine particle counting with aerodynamic particle focusing and corona charging, Atmos. Environ., 41, 5271-5279, 2007.

Unger, L., Boulaud, D., and Borra, J. P.: Unipolar field charging of particles by electrical discharge: effect of particle shape, J. Aerosol Sci., 35, 965-979, 2004.
Ude, S., and Fernández de la Mora, J.: Molecular monodisperse mobility and mass standards from electrosprays of tetra-alkyl ammonium halides, J. Aerosol Sci., 36, 1224-1237, 2005. 